\title{
Dose response of umeclidinium administered once or twice daily in patients with COPD: a randomised cross-over study
}

\author{
Alison Church ${ }^{1}$, Misba Beerahee $^{2^{*}}$, Jean Brooks ${ }^{3}$, Rashmi Mehta ${ }^{1}$ and Palvi Shah ${ }^{4}$
}

\begin{abstract}
Background: Umeclidinium bromide (UMEC) is an inhaled long-acting muscarinic antagonist in development for chronic obstructive pulmonary disease (COPD).

Methods: This was a multicentre, randomised, double-blind, placebo-controlled, three-way cross-over, incomplete block study to evaluate UMEC 15.6, 31.25, 62.5, and $125 \mu \mathrm{g}$ administered once daily (QD), and UMEC $15.6 \mu \mathrm{g}$ and $31.25 \mu \mathrm{g}$ administered twice daily (BID), over 7 days in patients with COPD. Tiotropium was included as an open-label treatment arm. The primary efficacy endpoint was trough forced expiratory volume in 1 second $\left(F E V_{1}\right)$ on Day 8. Secondary efficacy endpoints included weighted mean $\mathrm{FEV}_{1}$ over 0-24 hours after morning dosing on Day 7, and serial FEV ${ }_{1}$ at each time point over 24 hours after morning dosing on Day 7. Safety and pharmacokinetics were also examined.

Results: One hundred and sixty-three patients (mean age 59.5 years, 52\% female) were randomised. Based on the population dose-response model of trough $\mathrm{FEV}_{1}$ data, the geometric mean potency $\left(\mathrm{ED}_{50}\right)$ of UMEC was $37 \mu \mathrm{g}$ (95\% confidence interval $[\mathrm{Cl}]: 18,57)$ with a predicted maximum intrinsic efficacy $\left(E_{\max }\right)$ at trough of $0.185 \mathrm{~L}$ (95\% Cl: 0.153, 0.218) after QD dosing. UMEC $125 \mu \mathrm{g}$ QD demonstrated the greatest improvements in measure of lung function compared with doses of $62.5 \mu \mathrm{g}$ and below. UMEC $125 \mu \mathrm{g}$ QD exhibited more consistent increases in $\mathrm{FEV}_{1}$ from baseline across serial time points over 24 hours compared with other UMEC doses and tiotropium. Increases in FEV ${ }_{1}$ over 0-12 hours were similar to those observed over 12-24 hours after the second dose of UMEC was administered. UMEC was rapidly absorbed following inhaled dosing and eliminated from plasma. Adverse events, generally mild, were highest with UMEC $125 \mu \mathrm{g}$ QD (18\%) compared with placebo (8\%), tiotropium (4\%) and other UMEC doses (5-12\%).
\end{abstract}

Conclusions: UMEC is a potent QD bronchodilator with geometric mean $\mathrm{ED}_{50}$ of $37 \mu \mathrm{g}$. A dose ordering over the range of UMEC 15.6-125 $\mu \mathrm{g}$ QD doses was observed, with UMEC $125 \mu \mathrm{g}$ showing the greatest improvement in trough FEV 1 .

Trial registration: GlaxoSmithKline funded (clinicaltrials.gov NCT01372410; GlaxoSmithKline study number AC4115321).

Keywords: Chronic obstructive pulmonary disease (COPD), Long-acting bronchodilators, Long-acting muscarinic antagonist (LAMA), Umeclidinium (UMEC), GSK573719

\footnotetext{
* Correspondence: misba.2.beerahee@gsk.com

${ }^{2}$ Clinical Pharmacology Modelling \& Simulation, GlaxoSmithKline, Stevenage

SG1 2NY, UK

Full list of author information is available at the end of the article
}

\section{Biomed Central}

(c) 2014 Church et al.; licensee BioMed Central Ltd. This is an open access article distributed under the terms of the Creative Commons Attribution License (http://creativecommons.org/licenses/by/2.0), which permits unrestricted use, distribution, and reproduction in any medium, provided the original work is properly cited. 


\section{Background}

Cholinergic tone is considered the major reversible component of airflow obstruction in patients with chronic obstructive pulmonary disease (COPD) [1]. Receptor antagonism by antimuscarinic agents facilitates relaxation of airway smooth muscle. These agents bind to muscarinic receptor subtypes $M_{1}$ and $M_{3}$ localised in airway smooth muscle and block the bronchoconstrictor response to cholinergic nerve stimulation $[2,3]$, thereby improving airflow obstruction. Long-acting muscarinic antagonists (LAMAs) have been shown to be a more effective and convenient treatment for COPD than shortacting bronchodilators [4].

Umeclidinium bromide (UMEC; GSK573719) is an inhaled LAMA in development for the treatment of COPD. Pharmacology studies have demonstrated that single- and repeat-dose UMEC administration is well tolerated in healthy volunteers [5] and in patients with COPD [6,7]. Statistically significant improvements in change from baseline in trough forced expiratory volume in 1 second $\left(\mathrm{FEV}_{1}\right)$ were demonstrated compared with placebo $[6,8]$. Although the dose-response curve of UMEC from $62.5 \mu \mathrm{g}$ to $1000 \mu \mathrm{g}$ has been examined over 14 [6] and 28 days [8], the response obtained over this dosing range was relatively flat.

The current study examined the dose-response and safety of UMEC 15.6, 31.25, 62.5, and $125 \mu \mathrm{g}$ administered once daily (QD), and UMEC 15.6 and $31.25 \mu \mathrm{g}$ twice daily (BID). A model-based approach to the assessment of dose response has the advantage of utilising information within and across the range of doses studied for a more informed assessment of the drug's dose-response relationship [9]. Preliminary results have been presented in abstract form [10].

\section{Methods \\ Patients}

Study investigators enrolled eligible patients who were 40-80 years of age, had a clinical history of COPD as defined by the American Thoracic Society (ATS)/European Respiratory society [11], were current or former cigarette smokers with a history of cigarette smoking of $\geq 10$ packyears, and had a post-salbutamol $\mathrm{FEV}_{1} /$ forced vital capacity (FVC) ratio of $<0.70$ and a post-salbutamol $\mathrm{FEV}_{1}$ of $\geq 35 \%$ and $\leq 70 \%$ of predicted normal values [12,13]. Patients were excluded if they had a current diagnosis of asthma, known $\alpha 1$-antitrypsin deficiency, active lung infections, lung cancer, any clinically significant uncontrolled disease, or an abnormal and significant electrocardiogram (ECG) or significantly abnormal clinical laboratory finding. Concomitant use of inhaled salbutamol as a rescue medication was allowed. Inhaled corticosteroids (ICS) at a dose up to $1000 \mu \mathrm{g} /$ day of fluticasone propionate or equivalent were permitted, provided the dose remained stable throughout the treatment period. Initiation or discontinuation of ICS or long-acting $\beta_{2}$-agonist/ICS combinations within 30 days prior to screening was prohibited; however, patients were allowed to discontinue long-acting $\beta_{2}$-agonist/ICS up to 2 days prior to screening if ICS alone was continued.

Written consent was obtained prior to the start of study-specific procedures. The study (clinicaltrials.gov NCT01372410; GSK study number AC4115321) was approved by the local ethics review committee (Chesapeake IRB, Columbia, MD) and was conducted in accordance with the Declaration of Helsinki and Good Clinical Practice guidelines [14].

\section{Study design and treatment}

This randomised, incomplete block, three-period crossover, placebo-controlled study was conducted in 15 centres in the United States from 25 July 2011 to 27 October 2011. In accordance with the randomisation schedule, generated using SAS and RandAll version 2.5, patients were assigned to receive a sequence of three of eight potential treatments for a total of three treatment periods per patient. UMEC $15.6 \mu \mathrm{g}$ QD, $31.25 \mu \mathrm{g}$ QD, $62.5 \mu \mathrm{g}$ QD, $125 \mu \mathrm{g}$ QD, $15.6 \mu \mathrm{g}$ BID, $31.25 \mu \mathrm{g}$ BID, open-label tiotropium $18 \mu \mathrm{g}$ QD, and placebo were evaluated. UMEC and matching placebo study medication were administered via the ELLIPTA ${ }^{\text {su }}$ dry powder inhaler ${ }^{a}$ in a double-blind fashion where neither patients nor the study investigators knew which study medication was administered. Tiotropium was an open-label comparator administered via the Handihaler ${ }^{\circledR}$. To maintain blinding, patients taking QD treatments also took placebo in the evening. Treatment consisted of three 7-day treatment periods, with two intervening 10-14 day washout periods. A 7-9 day washout period followed the third treatment period, before a follow-up phone call.

Study withdrawal criteria included COPD exacerbation (defined as acute worsening of COPD symptoms requiring treatment beyond study medication or rescue salbutamol, including antibiotics or systemic corticosteroids, and/ or hospitalisation or emergency treatment), clinically significant change in laboratory parameters, or elevated liver chemistry.

Treatment adherence was assessed on Day 7 of each treatment period using dose counters on the inhaler or by counting blister doses remaining (tiotropium).

\section{Outcomes and assessments}

The primary efficacy endpoint was trough $\mathrm{FEV}_{1}$ on Day 8 , defined as the mean of the $\mathrm{FEV}_{1}$ values obtained 23 and 24 hours after morning dosing on Day 7 of each treatment period.

The secondary efficacy endpoints were weighted mean $\mathrm{FEV}_{1}$ over $0-24$ hours after morning dosing on Day 7 , and serial $\mathrm{FEV}_{1}$ over 24 hours after morning dosing on Day 7. Serial spirometry was measured 30 and 5 minutes 
pre-morning dose, 1, 3, 6, 9, 12 (pre-evening dose), 13, 15, 23 and 24 hours after morning dosing.

Additional efficacy endpoints included trough $\mathrm{FEV}_{1}$ at other time points, weighted mean $\mathrm{FEV}_{1}$ over other time periods, serial $\mathrm{FEV}_{1}$, trough $\mathrm{FVC}$, weighted mean $\mathrm{FVC}$, and rescue salbutamol use (mean number of puffs per day and percentage of rescue-free days). Safety assessments included incidence of adverse events (AEs), haematology and clinical chemistry evaluations, incidence of COPD exacerbations, and vital signs.

Plasma and urine samples were collected for pharmacokinetic (PK) analysis. Assessments included area under concentration-time curve from time 0 to time $\mathrm{t}\left(\mathrm{AUC}_{(0-\mathrm{t})}\right)$, maximum observed plasma concentration $\left(\mathrm{C}_{\max }\right)$, time of maximum observed plasma concentration $\left(\mathrm{t}_{\max }\right)$, amount of drug excreted unchanged in urine, and fraction of dose excreted unchanged in urine. Accumulation was calculated using plasma $\mathrm{C}_{\max }$, plasma AUC using a common sampling time and amount excreted in urine over the same time interval on Day 7 versus Day 1.

\section{Spirometry measurements}

Measurements for $\mathrm{FEV}_{1}$ and $\mathrm{FVC}$ were obtained using standard spirometry equipment that met or exceeded the minimal ATS performance recommendations [15]. Spirometry was performed at screening, during a 6-hour interval on the first day of each treatment period, and during a 24-hour interval on the last day of each treatment period. A minimum of three acceptable spirometry efforts were obtained for $\mathrm{FEV}_{1}$ and FVC, and the highest measurement was recorded. Pre- and post-salbutamol spirometry measures at screening determined patient eligibility.

\section{Sample size determination}

The sample size for the population model-based dose response analysis was determined using the Monte-Carlo Mapped Power approach for mixed effects [16]. The dose response from a UMEC dose-ranging study was used as reference [6]. Using a model-based approach for a cross-over design study, 16 patients would provide at least $90 \%$ power to show a significant dose response with 25 patients showing $95 \%$ power. The sample size was increased to reduce the risk of a false positive result for the lower UMEC doses - a sample size of 40 patients per arm would provide $<10 \%$ chance that lower doses of UMEC would falsely show a trough $\mathrm{FEV}_{1}$ response of $>100 \mathrm{~mL}$. This number of patients would also provide approximately $85 \%$ power for the comparison of active treatments with placebo for the primary efficacy endpoint on Day 8 (ANCOVA analysis). This calculation assumes a two-sided 5\% significance level, a within-patient standard deviation of $0.170 \mathrm{~L}$ (based on Donohue et al. [6]) and a treatment difference from placebo of $0.130 \mathrm{~L}$. Therefore, approximately 160 patients were recruited to compensate for a possible $30 \%$ dropout rate.

\section{Study population}

The primary population for all efficacy and safety analyses was the modified intent-to-treat (mITT) population, comprising all patients who were randomised and received at least one dose of study medication. The population was modified in that outcomes were analysed based on the actual treatment received rather than the randomised treatment. The PK population comprised all patients in the mITT population for whom a PK sample was obtained and analysed.

\section{Model-based and statistical analysis}

Two approaches were used to characterise the relationship between dose and trough $\mathrm{FEV}_{1}$. The first approach (i.e., the primary analysis) was a model-based analysis whereby an $\mathrm{E}_{\max }$ model was selected from a suite of dose response shape models to describe the observed trough $\mathrm{FEV}_{1}$ data as a function of dose. Two key parameters were estimated from this model $-\mathrm{E}_{\max }$ which is an estimate of the maximum response predicted by the model given the observed trough $\mathrm{FEV}_{1}$ and $\mathrm{ED}_{50}$ which represents the dose that achieves $50 \%$ of $E_{\max }$. The modelling approach investigated the impact of the inter-patient variability in trough $\mathrm{FEV}_{1}$ by examining the influence of patient demographic and physiologic factors (Additional file 1), and the effect of QD and BID regimen on the model parameters. Established model diagnostics were derived $[17,18]$ to demonstrate the suitability of the chosen dose-response model. Using the population $E_{\max }$ model, the predictive distribution of trough $\mathrm{FEV}_{1}$ across treatments was derived by simulating 1000 sets of individual model parameters using the covariance matrix (model uncertainty and random effects) of parameter estimates from the model. Key outputs included median trough $\mathrm{FEV}_{1}$ (95th percentiles) for QD and BID regimens, the probability of achieving a certain target trough $\mathrm{FEV}_{1}$ with each dose (adjusted for baseline and placebo), and median estimates of trough $\mathrm{FEV}_{1}$ (adjusted for baseline and placebo) across the dose range and by dose regimen. Both mean baseline $\mathrm{FEV}_{1}$ and period were included as covariates.

A Day 8 dataset and a pooled dataset for Days 7 and 8 (post-hoc analysis) were analysed and reported for the primary efficacy analysis. The rationale for pooling Day 7 and Day 8 was to ensure informative interpretation of $\mathrm{FEV}_{1}$ response as function of dose, given the repeated measures for trough $\mathrm{FEV}_{1}$ response within each patient on different days.

The second approach (also referred to as the secondary analysis) involved comparison of trough $\mathrm{FEV}_{1}$ at each dose versus placebo using Analysis of Covariance (ANCOVA). The change from baseline $\mathrm{FEV}_{1}$ (defined as the mean of 
the two pre-morning dose assessments at Day 1) to trough $\mathrm{FEV}_{1}$ at Day 8 was analysed using a mixed model which included period baseline $\mathrm{FEV}_{1}$, mean baseline $\mathrm{FEV}_{1}$, treatment and period as fixed effects, and patient as a random effect. A similar methodology was used to analyse weighted mean $\mathrm{FEV}_{1}$ and trough and weighted mean FVC endpoints. Serial $\mathrm{FEV}_{1}$ was analysed using a similar mixed model. Sensitivity analyses were conducted to assess the effect of any interaction of treatment with mean baseline, period baseline or period by repeating the analysis of trough $\mathrm{FEV}_{1}$ on Day 8 and adding a variable to indicate the previous treatment received, removing baselines from the model or both.

Due to issues with Good Clinical Practice at one investigator site, a decision was made after unblinding to re-evaluate the dose-response model and ANCOVA analysis of trough $\mathrm{FEV}_{1}$ on Day 8, excluding all patients enrolled at that site.

A Bayesian analysis of the primary endpoint (using the same covariates as the original mixed-model analysis) provided the posterior probability distribution of the treatment difference of each treatment against placebo, i.e. the distribution of the true treatment difference given the data observed in the study.

\section{Results}

\section{Study population}

Two hundred and forty-four patients were screened, 163 were randomised (mITT population; Figure 1), and $90 \%$ completed the study. Mean treatment compliance was $\geq 99.3 \%$ across all treatment periods.

Patient demographics and baseline clinical characteristics are summarised in Table 1 . Overall, the study population had moderate to severely impaired airflow obstruction at screening, as evident by values for mean post-bronchodilator $\mathrm{FEV}_{1}$ and $\mathrm{FEV}_{1} / \mathrm{FVC}$ ratio, and mean post-salbutamol $\mathrm{FEV}_{1}$ and FVC. Across treatment groups, $20-32 \%$ of patients took concomitant COPD medication, most often ICSs (18-30\%) followed by oxygen (4-8\%).

\section{Efficacy}

\section{Final dose-response model}

The physiological $E_{\max }$ model (see Additional file 2) was optimal in defining the relationship between UMEC doses

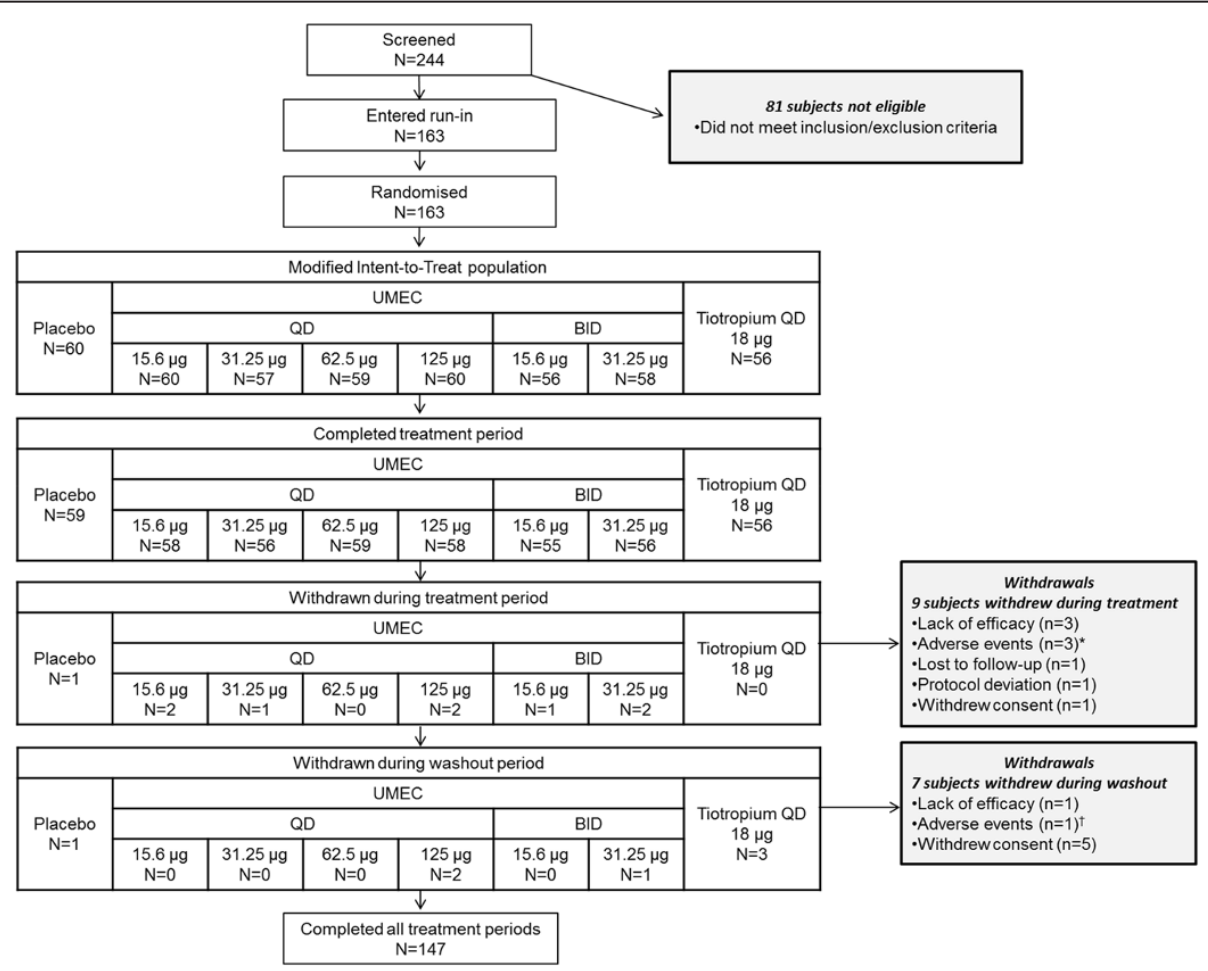

Figure 1 Patient disposition and CONSORT flow chart. *1 patient each in UMEC 15.6 $\mu \mathrm{g}$ QD (acute respiratory failure), UMEC $31.25 \mu \mathrm{g}$ QD (myocardial infarction), and UMEC $31.25 \mu \mathrm{g}$ BID (dizziness) during active treatment. ${ }^{\dagger} 1$ patient in UMEC $125 \mu \mathrm{g}$ QD (nasopharyngitis) during washout. Number of patients $(N)$ for completed treatment period, withdrawn during treatment period, and withdrawn during washout period reflects the total number of patients in each treatment group across all three treatment periods who completed the treatment period, withdrew during the treatment period, or withdrew during the washout period; two patients included in the counts for 'withdrawn during a treatment period' and not included in the counts and percentages for 'withdrawn during a washout period' actually withdrew during a washout period. BID, twice daily; QD, once daily; UMEC, umeclidinium bromide. 
Table 1 Summary of patient population (mlTT population), (a) demographic characteristics (b) screening parameters

\begin{tabular}{lc}
\hline a. & Total \\
\cline { 2 - 2 } Characteristic & $\mathbf{N}=\mathbf{1 6 3}$ \\
\hline Age (yr) & $59.5(9.21)$ \\
Mean (SD) & \\
Sex, $n$ (\%) & $78(48)$ \\
Male & \\
Ethnicity, $n$ (\%) & $1(<1)$ \\
Hispanic/Latino & $162(>99)$ \\
Non-Hispanic/Latino & $145(89)$ \\
Race, $n$ (\%) & $16(10)$ \\
White & $1(<1)$ \\
African American/African heritage & $1(<1)$ \\
African American/African & \\
heritage and White & \\
American Indian or Alaskan native & $170.2(9.20)$ \\
Height (cm) & \\
Mean (SD) & $79.55(17.539)$ \\
Weight (kg) & \\
Mean (SD) & $27.36(5.115)$ \\
Body mass index (kg/m²) &
\end{tabular}

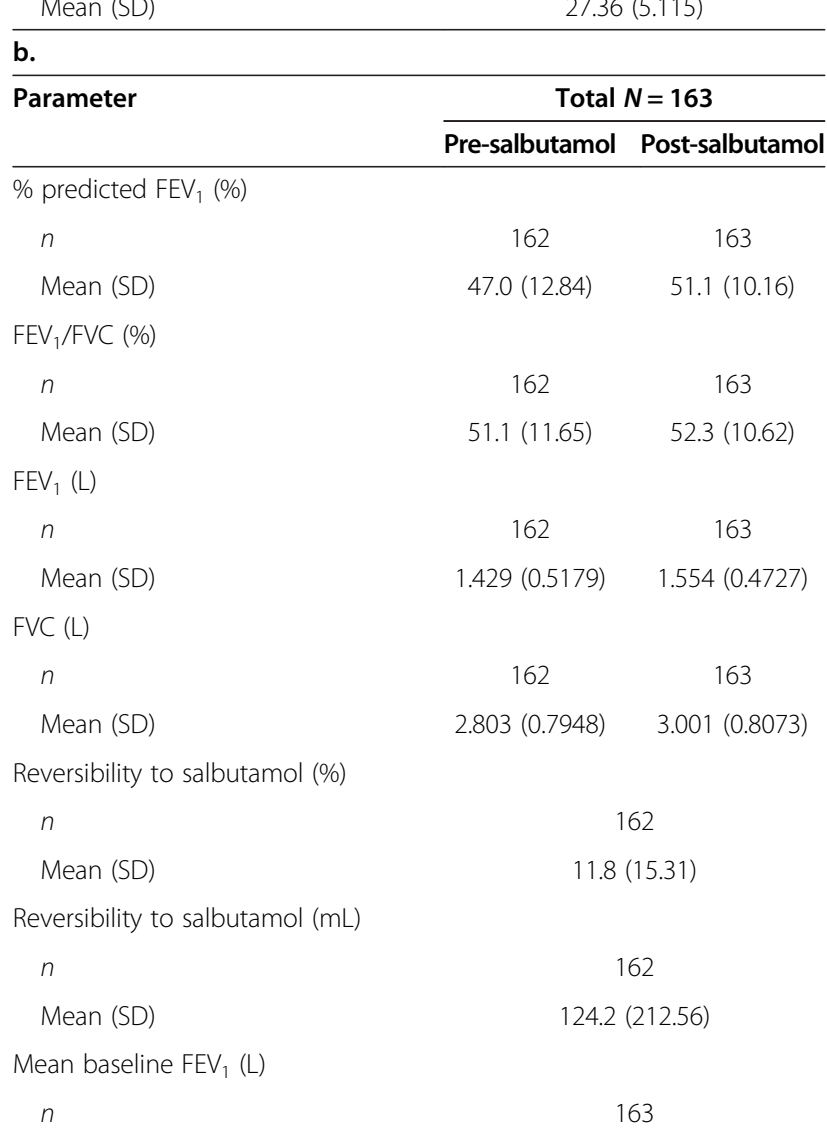

Table 1 Summary of patient population (mITT population), (a) demographic characteristics (b) screening parameters (Continued)

\begin{tabular}{lc}
\hline Mean (SD) & $1.408(0.5282)$ \\
Mean baseline FVC $(\mathrm{L})$ & 163 \\
$n$ & $2.763(0.7920)$ \\
\hline
\end{tabular}

Note: mean baseline was defined as the mean of the baseline values from each treatment period. If one or more values were missing, the mean baseline was the mean of the non-missing values.

FEV $_{1}$, forced expiratory volume in 1 second; FVC, forced vital capacity; $\mathrm{mITT}$ modified intent-to-treat; SD, standard deviation; UMEC, umeclidinium bromide.

and the primary endpoint of trough $\mathrm{FEV}_{1}$ on Day 8; the parameters of the model were estimated with high precision (coefficient of variation $<30 \%$ ). The $\mathrm{ED}_{50}$ for UMEC QD dosing was $37 \mu \mathrm{g}(95 \% \mathrm{CI}: 18-57)$. The predicted $\mathrm{E}_{\max }$ was $0.185 \mathrm{~L}$ (95\% CI: 0.153, 0.218). Model diagnostics show suitability of the final model in describing the doseresponse relationship (see Additional file 3). Pooled data from Day 7 and Day 8 were similar: $\mathrm{ED}_{50}$ of $38 \mu \mathrm{g}$ and predicted $\mathrm{E}_{\max }$ of $0.156 \mathrm{~L}$.

The model-based simulated median estimates of $\mathrm{FEV}_{1}$ for the QD regimen were plotted together with the observed least square (LS) mean $\mathrm{FEV}_{1}$ treatment differences (ANCOVA analysis) (Figure 2a). Both methods showed reasonable agreement in the $\mathrm{FEV}_{1}$ response with dose with the model-based analysis showing a clear monotonic dose response. The dose-response curve suggests that trough $\mathrm{FEV}_{1}$ response did not plateau at the highest dose. Results of the post-hoc model analysis excluding one investigator site (due to issues of Good Clinical Practice) were generally consistent with those for the mITT population (Figure $2 \mathrm{~b}$ ). Similar trends were also observed for the BID regimen in the mITT (Figure 2c) and the post-hoc model analysis excluding one investigator site (Figure 2d).

Simulation based on the final dose-response model was used to estimate the probability of achieving a particular response at a given dose (Table 2); this application of the model utilised the integrated variability between- and within-patients across doses to provide a better insight into the dose-response relationship. Thus, UMEC $62.5 \mu \mathrm{g}$ and $125 \mu \mathrm{g}$ QD had a $\geq 87 \%$ probability of exceeding the minimum clinically relevant target of $0.100 \mathrm{~L}$ trough $\mathrm{FEV}_{1}[6]$ and a $\geq 77 \%$ probability of exceeding a $0.120 \mathrm{~L}$ trough $\mathrm{FEV}_{1}$ (Table 2). Based on the total daily UMEC dose, the model-based analysis suggests that although there were small numerical differences between the $31.25 \mu \mathrm{g}$ QD and $15.6 \mu \mathrm{g}$ BID dosing regimens, the probability of exceeding the target response with the $31.25 \mu \mathrm{g}$ BID dose is markedly lower than that for the $62.5 \mu \mathrm{g}$ QD dose (Table 2). 


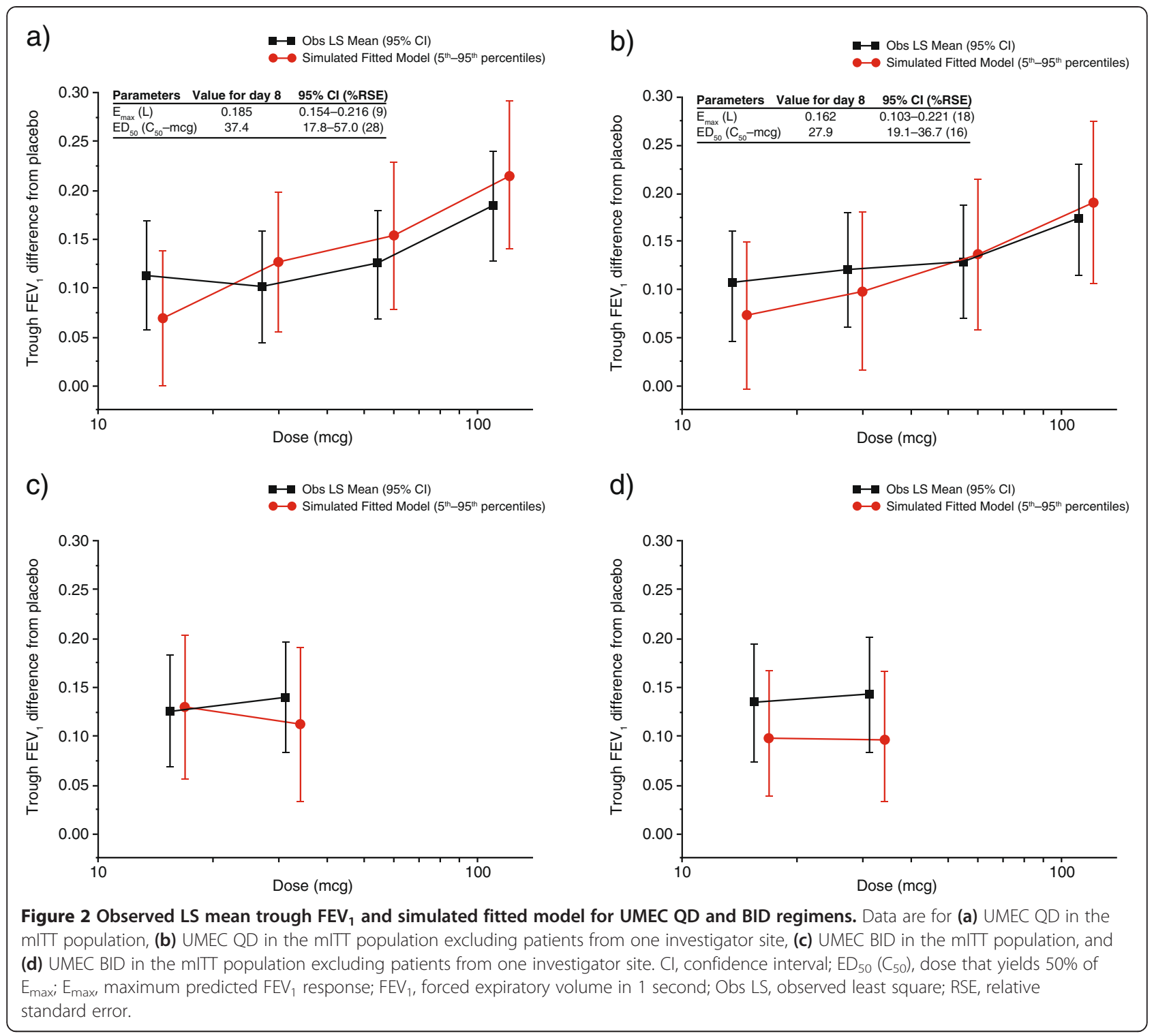

Table 2 Probability of a dose exceeding a target response (adjusted for placebo) (mITT population)

\begin{tabular}{|c|c|c|c|c|}
\hline \multirow[t]{2}{*}{ UMEC dose } & \multicolumn{4}{|c|}{$\begin{array}{l}\text { Probability (\%) of exceeding a specified change } \\
\text { from baseline } \mathrm{FEV}_{1} \text { at trough (Day } 8 \text { dataset) }\end{array}$} \\
\hline & $0.075 \mathrm{~L}$ & $0.100 \mathrm{~L}$ & $0.120 \mathrm{~L}$ & $0.150 \mathrm{~L}$ \\
\hline $15.6 \mu \mathrm{g}$ QD & 43 & 21 & 11 & 3 \\
\hline $31.25 \mu \mathrm{g}$ QD & 88 & 74 & 56 & 30 \\
\hline $62.5 \mu \mathrm{g}$ QD & 95 & 87 & 77 & 52 \\
\hline $125 \mu \mathrm{g} Q \mathrm{Q}$ & 99 & 100 & 99 & 92 \\
\hline $15.6 \mu \mathrm{g} \mathrm{BID}$ & 89 & 75 & 59 & 33 \\
\hline $31.25 \mu \mathrm{g} \mathrm{BID}$ & 78 & 60 & 44 & 21 \\
\hline
\end{tabular}

$\mathrm{BID}$, twice daily; $\mathrm{FEV}_{1}$, forced expiratory volume in 1 second; $\mathrm{QD}$, once daily; UMEC, umeclidinium bromide.

\section{Trough FEV 1 on Day 8 (ANCOVA analysis)}

Statistically significant increases in change from baseline in trough $\mathrm{FEV}_{1}$ over placebo on Day 8 were demonstrated for all UMEC QD and BID doses (range: 0.101-0.183 L; $p<0.001$ for each comparison); tiotropium $(0.101 \mathrm{~L}$; $p<0.001)$ was within the range observed for UMEC doses (Figure 3). Dose ordering was observed across UMEC QD doses with UMEC $125 \mu \mathrm{g}$ QD demonstrating the greatest improvements in trough $\mathrm{FEV}_{1}$. There was some evidence of an interaction of treatment with period baseline $(p=0.0014)$ and period $(p=0.0193)$. The conclusions from each sensitivity analysis performed to assess the impact of these interactions were similar to those from the predefined analysis and it was therefore concluded that any interaction with baseline was not significantly impacting study conclusions. 


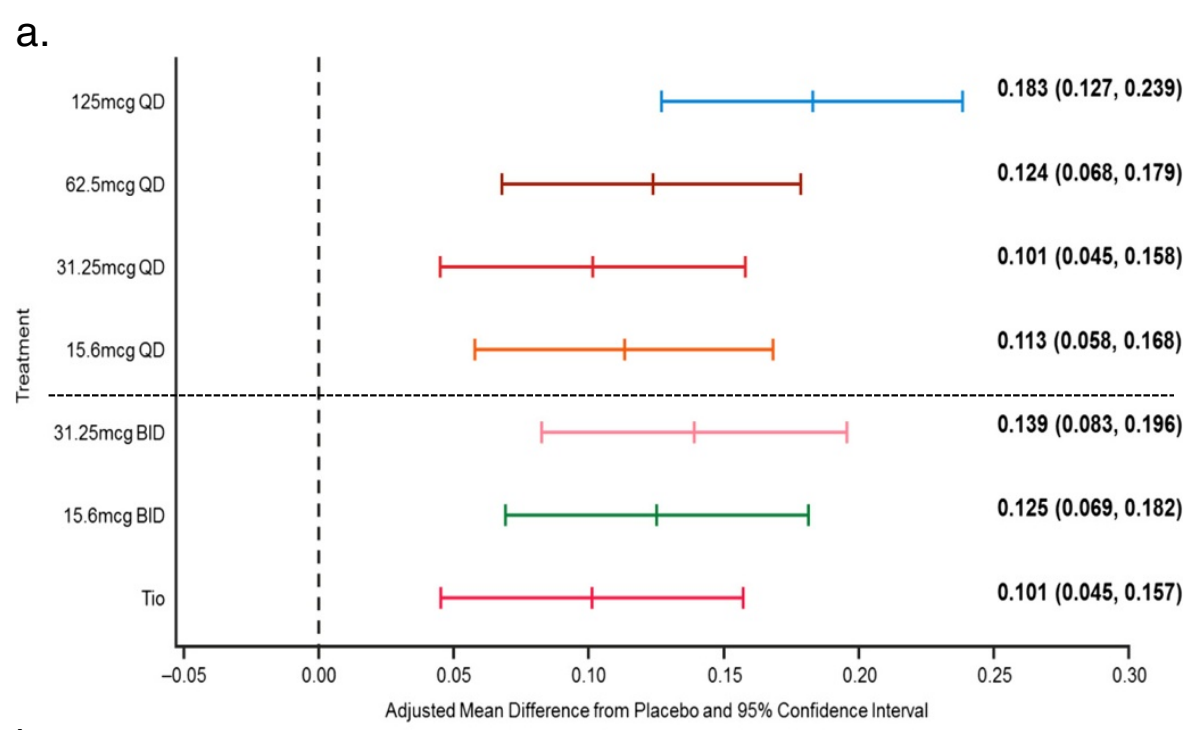

b.

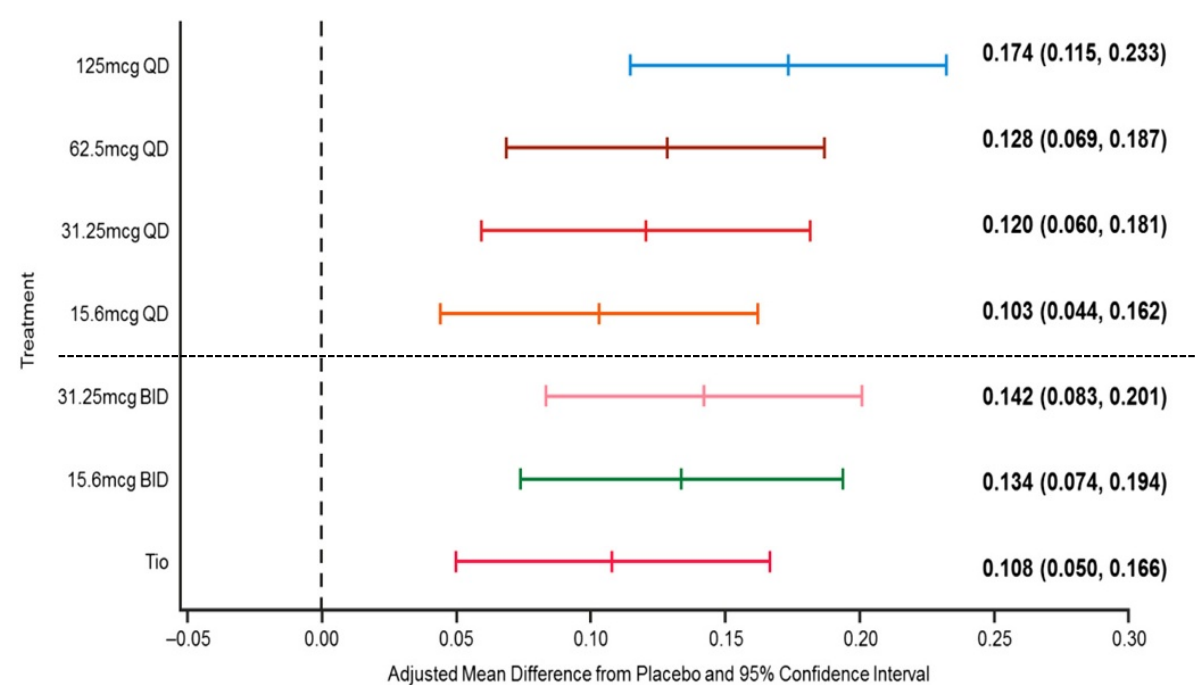

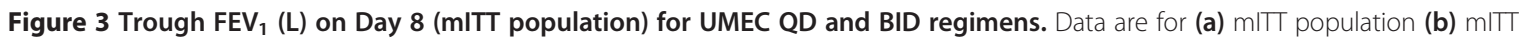
population excluding patients from one investigator site. BID, twice daily; $Q D$, once daily.

Bayesian analysis demonstrated that UMEC $62.5 \mu \mathrm{g}$ and $125 \mu \mathrm{g}$ QD showed high probabilities (80.1\% and 99.8\%, respectively) that the true treatment difference compared with placebo was greater than $0.100 \mathrm{~L}$ for trough $\mathrm{FEV}_{1}$ on Day 8. The probabilities for $15.6 \mu \mathrm{g}$ and $31.25 \mu \mathrm{g}$ QD were 68.2\% and 52.0\%, respectively. Additionally, UMEC $125 \mu \mathrm{g}$ QD showed a $96.8 \%$ probability of having a true treatment difference from placebo of greater than $0.130 \mathrm{~L}$ as compared to tiotropium which showed a $15.9 \%$ probability.

\section{0-24-hour weighted mean $\mathrm{FEV}_{1}$ on Day 7}

Statistically significant improvements in the adjusted mean changes from baseline in 0-24-hour weighted mean $\mathrm{FEV}_{1}$ over placebo on Day 7 were observed for all UMEC QD and BID doses and for tiotropium (Table 3). Dose ordering was observed across QD dose regimens with UMEC $125 \mu \mathrm{g}$ QD showing the greatest improvements in $0-$ 24-hour weighted mean $\mathrm{FEV}_{1}$.

\section{Serial FEV 1 over 24 hours on Day 7}

Serial FEV $V_{1}$ over time on Day 7 demonstrated statistically significant improvements in the adjusted mean changes from baseline over placebo for all UMEC doses and tiotropium at all time points (Figure 4). Increases were broadly consistent across all time points over 24 hours, with no marked improvement in $\mathrm{FEV}_{1}$ for either BID dose following a second UMEC dose at 12 hours. Improvements in $\mathrm{FEV}_{1}$ over placebo observed at time points over the first 12 hours were maintained over the second 12 hours for all UMEC QD doses, which is in contrast to an observed 
Table 3 0-24-hour weighted mean FEV $_{1}$ (L) on Day 7 (mITT population)

\begin{tabular}{|c|c|c|c|c|c|}
\hline \multirow{3}{*}{$\begin{array}{l}\text { 0-24-hour weighted } \\
\text { mean FEV }{ }_{1}(\mathrm{~L})\end{array}$} & \multirow{3}{*}{$\begin{array}{c}\text { Placebo } \\
N=60\end{array}$} & \multicolumn{4}{|c|}{ UMEC QD } \\
\hline & & \multirow{2}{*}{$\begin{array}{l}15.6 \mu \mathrm{g} \\
N=60\end{array}$} & \multirow{2}{*}{$\begin{array}{c}31.25 \mu \mathrm{g} \\
N=57\end{array}$} & \multirow{2}{*}{$\begin{array}{c}62.5 \mu \mathrm{g} \\
N=59\end{array}$} & \multirow{2}{*}{$\begin{array}{l}125 \mu \mathrm{g} \\
N=60\end{array}$} \\
\hline & & & & & \\
\hline N & 54 & 56 & 51 & 54 & 56 \\
\hline LS mean (SE) & $1.327(0.018)$ & $1.443(0.018)$ & $1.445(0.019)$ & $1.459(0.018)$ & $1.500(0.018)$ \\
\hline LS mean change (SE) & $-0.074(0.018)$ & $0.043(0.018)$ & $0.045(0.019)$ & $0.059(0.018)$ & $0.100(0.018$ \\
\hline Difference from placebo & NA & 0.116 & 0.118 & 0.132 & 0.173 \\
\hline $95 \% \mathrm{Cl}$ & NA & $(0.072,0.160)$ & $(0.073,0.163)$ & $(0.087,0.178)$ & $(0.129,0.217)$ \\
\hline$p$-value & NA & $<0.001$ & $<0.001$ & $<0.001$ & $<0.001$ \\
\hline 0-24-hour & \multicolumn{4}{|c|}{ UMEC BID } & Tiotropium \\
\hline weighted mean $\mathrm{FEV}_{1}$ (L) & & & & & QD $18 \mu \mathrm{g}$ \\
\hline & & & & & $N=56$ \\
\hline N & & & & & 53 \\
\hline LS mean (SE) & & & & & $1.484(0.018)$ \\
\hline LS mean change (SE) & & & & & $0.084(0.018)$ \\
\hline Difference from placebo & & & & & 0.157 \\
\hline $95 \% \mathrm{Cl}$ & & & & & $(0.113,0.202)$ \\
\hline$p$-value & & & & & $<0.001$ \\
\hline
\end{tabular}

Note: Analysis performed using a mixed model with covariates of trough mean baseline, trough period baseline, treatment and period as fixed effects and subject as a random effect.

For each treatment period, baseline was defined as the mean of the values obtained 5 and 30 minutes predose on Day 1.

$\mathrm{BID}$, twice daily; $\mathrm{Cl}$, confidence interval; $\mathrm{FEV}_{1}$, forced expiratory volume in 1 second; LS, least square; mIT, modified intent-to-treat; NA, not applicable; QD, once daily; SE, standard error; UMEC, umeclidinium bromide.

decline in $\mathrm{FEV}_{1}$ improvement at time points over the second 12 hours for tiotropium.

\section{Trough FEV 1 on Day 7}

Statistically significant improvements in the adjusted mean changes from baseline in trough $\mathrm{FEV}_{1}$ over placebo on Day 7 were demonstrated for all UMEC QD and BID doses and for tiotropium (Table 4). The greatest improvement over placebo was observed for UMEC $125 \mu \mathrm{g}$ QD $(0.120 \mathrm{~L})$. Improvements in trough $\mathrm{FEV}_{1}$ with UMEC compared with placebo on Day 7 were lower than improvements in trough $\mathrm{FEV}_{1}$ observed on Day 8, although a dose ordering was maintained with UMEC $125 \mu \mathrm{g}$ QD providing the greatest improvement over both days.

\section{0-12-hour and 12-24-hour weighted mean FEV 1 on Day 7} Improvements in the adjusted mean changes from baseline for UMEC QD doses in 12-24-hour weighted mean $\mathrm{FEV}_{1}$ over placebo were generally similar or greater than those observed for 0-12-hour weighted mean $\mathrm{FEV}_{1}$, indicating sustained duration of action (Table 5). The ratios of evening (12-24 hours) to morning (0-12 hours) weighted mean $\mathrm{FEV}_{1}$ values were approximately 1.0 for all UMEC QD and BID doses; whereas the ratio for tiotropium was approximately 0.8 (Table 6). Dose ordering was observed across the QD regimens with UMEC $125 \mu \mathrm{g}$ having the largest effect in both 0-12-hour and 12-24-hour weighted mean $\mathrm{FEV}_{1}$.

\section{Trough and weighted mean on Day 7}

Statistically significant increases in the adjusted mean changes from baseline in trough and 0-24-hour weighted mean FVC over placebo on Day 7 were demonstrated for all UMEC QD and BID doses. Improvements in trough FVC ranged from $0.128-0.181 \mathrm{~L}(p \leq 0.006)$ for UMEC doses and $0.126(p<0.006)$ for tiotropium, and improvements in 0-24-hour weighted mean FVC ranged from $0.181-0.247 \mathrm{~L}(p<0.001)$ for UMEC doses and 0.233 $(p<0.001)$ for tiotropium. Dose ordering was observed across QD doses for trough FVC and weighted mean FVC with UMEC $125 \mu \mathrm{g}$, showing the largest improvements compared with placebo. FVC values over 24 hours on Day 7 demonstrated statistically significant differences compared with placebo for all UMEC QD and BID doses and tiotropium.

\section{Rescue salbutamol}

Dose ordering was observed across UMEC QD doses for reductions in rescue salbutamol use compared with placebo which was consistent with the observed $\mathrm{FEV}_{1}$ response: UMEC $125 \mu \mathrm{g}$ (0.804 puffs/day), $62.5 \mu \mathrm{g}$ (0.464 puffs/day), $31.25 \mu \mathrm{g}$ (0.283 puffs/day), and $15.6 \mu \mathrm{g}$ (0.254 puffs/day). 


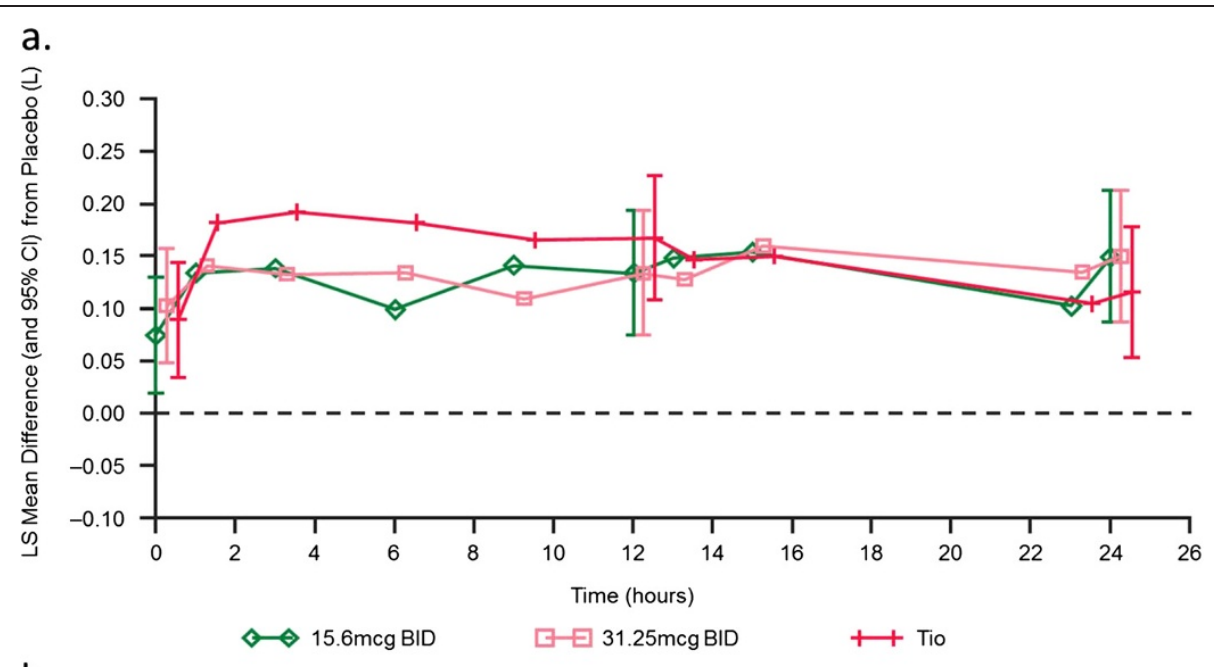

b.

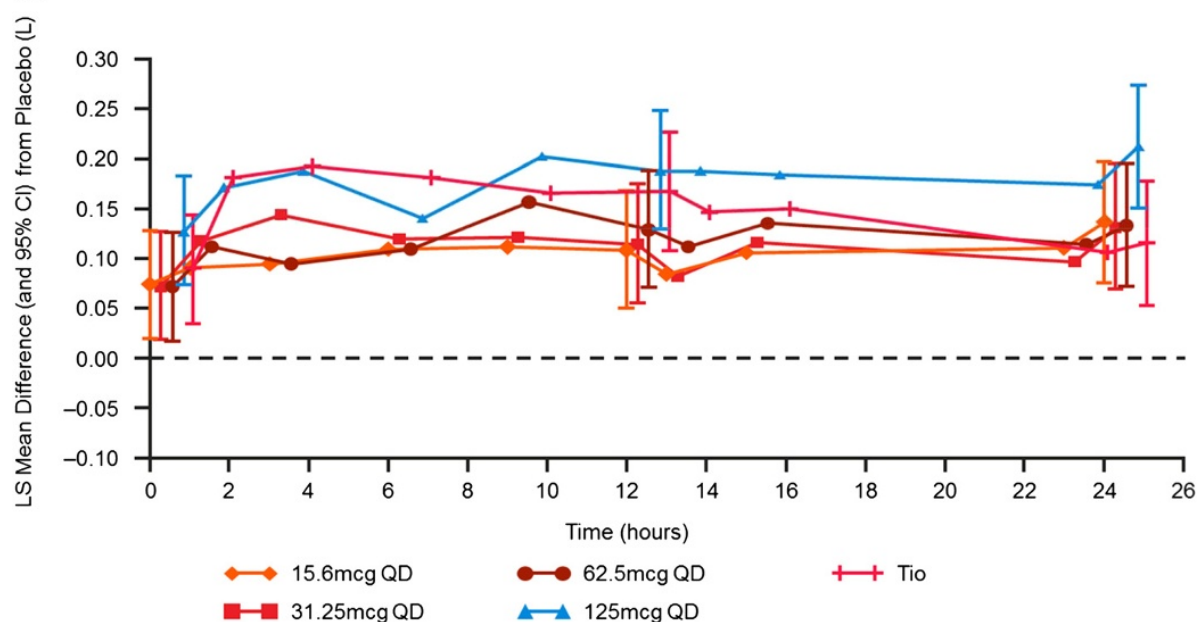

Figure 4 Serial FEV $_{1}$ on Day 7 adjusted treatment differences from baseline. Data are for (a) UMEC QD and tiotropium, and (b) UMEC BID and tiotropium (mITT population). BID, twice daily; Cl, confidence interval; LS, least square; QD once daily; Tio, tiotropium.

Tiotropium demonstrated a greater reduction in rescue salbutamol use compared with placebo (0.98 puffs/day) than those observed with UMEC. Increases from baseline in the percentage of rescue-free days demonstrated dose ordering: UMEC $125 \mu \mathrm{g}(15.72 \%), 62.5 \mu \mathrm{g}$ (12.50\%), $31.25 \mu \mathrm{g}$ (9.36\%), and $15.6 \mu \mathrm{g}(4.58 \%)$. Increases from baseline were also observed for tiotropium (11.32\%).

\section{Pharmacokinetics}

The plasma concentration profile for UMEC indicated that $C_{\max }$ occurred early (median $t_{\max }$ of 5-15 minutes) with doses above $31.25 \mu \mathrm{g}$ QD showing a median $t_{\text {last }}$ of 15 minutes, which was the last collected PK sample. The lower limit of UMEC quantification $(10 \mathrm{pg} / \mathrm{mL})$ and limited number of samples collected were not sufficient to fully characterise its PK profile; $46 \%$ of data were nonquantifiable. Comparison of UMEC QD and BID dosing regimens suggested that systemic exposure (i.e. AUC and $C_{\max }$ ) was higher following QD dosing than BID dosing for the same total daily dose. Following 7 days repeat dosing, the accumulation ratio ranged from 1.2 to 1.7 for UMEC systemic exposure. Approximately $2.2-2.5 \%$ of the total dose was excreted unchanged in urine in 24 hours after QD doses. Urine excretion of UMEC increased with dose, and the amount of UMEC excreted in the urine following Day 1 dose was lower than that following Day 7 dose for all dose levels.

\section{Safety}

Overall incidence of AEs was low across treatments (4-18\%). The most frequently reported AEs are shown in Table 7. Two serious AEs (acute respiratory failure, UMEC 15.6 $\mu \mathrm{g}$ QD and myocardial infarction UMEC $31.25 \mu \mathrm{g}$ QD) were reported; neither was fatal or considered treatment-related by the investigator. Four COPD exacerbations were reported: one (placebo), two (UMEC $15.6 \mu \mathrm{g}$ QD), and one (UMEC $125 \mu \mathrm{g}$ QD). 


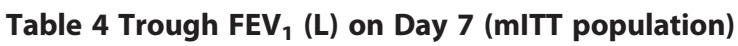

\begin{tabular}{|c|c|c|c|c|c|}
\hline \multirow[t]{3}{*}{ Trough FEV $_{1}$ (L) } & \multirow[b]{2}{*}{ Placebo } & \multicolumn{4}{|c|}{ UMEC QD } \\
\hline & & $15.6 \mu \mathrm{g}$ & $31.25 \mu \mathrm{g}$ & $62.5 \mu \mathrm{g}$ & $125 \mu \mathrm{g}$ \\
\hline & $N=60$ & $N=60$ & $N=57$ & $N=59$ & $N=60$ \\
\hline N & 60 & 59 & 56 & 59 & 60 \\
\hline LS mean (SE) & $1.401(0.019)$ & $1.469(0.019)$ & $1.482(0.020)$ & $1.475(0.019)$ & $1.521(0.019)$ \\
\hline LS mean change (SE) & $-0.014(0.019)$ & $0.054(0.019)$ & $0.067(0.020)$ & $0.060(0.019)$ & $0.106(0.019)$ \\
\hline Difference from placebo & N/A & 0.068 & 0.081 & 0.074 & 0.120 \\
\hline $95 \% \mathrm{Cl}$ & $\mathrm{N} / \mathrm{A}$ & $(0.018,0.118)$ & $(0.030,0.131)$ & $(0.024,0.124)$ & $(0.070,0.170)$ \\
\hline$p$-value & N/A & 0.007 & 0.002 & 0.004 & $<0.001$ \\
\hline \multirow[t]{3}{*}{ Trough FEV $_{1}$ (L) } & \multicolumn{4}{|c|}{ UMEC BID } & Tiotropium QD \\
\hline & \multicolumn{2}{|c|}{$15.6 \mu \mathrm{g}$} & \multicolumn{2}{|c|}{$31.25 \mu \mathrm{g}$} & $18 \mu \mathrm{g}$ \\
\hline & \multicolumn{2}{|c|}{$N=56$} & \multicolumn{2}{|c|}{$N=58$} & $N=56$ \\
\hline N & \multicolumn{2}{|c|}{55} & \multicolumn{2}{|c|}{57} & 56 \\
\hline LS mean (SE) & \multicolumn{2}{|c|}{$1.484(0.020)$} & \multicolumn{2}{|c|}{$1.500(0.020)$} & $1.493(0.020)$ \\
\hline LS mean change (SE) & & & & & $0.078(0.020)$ \\
\hline Difference from placebo & & & & & 0.092 \\
\hline $95 \% \mathrm{Cl}$ & & & & & $(0.041,0.142)$ \\
\hline$p$-value & & & & & $<0.001$ \\
\hline
\end{tabular}

Analysis performed using a mixed model with covariates of period baseline, mean baseline, treatment and period as fixed effects and patient as a random effect; for each treatment period, baseline was defined as the mean of the values obtained 5 and 30 minutes pre-dose on Day 1 and trough FEV ${ }_{1}$ is calculated from the $\mathrm{FEV}_{1}$ values obtained 23 and 24 hours after the Day 6 morning dose.

$\mathrm{BID}$, twice daily; $\mathrm{Cl}$, confidence interval; $\mathrm{FEV}_{1}$, forced expiratory volume in 1 second; LS, least square; mITT, modified intent-to-treat; N/A, not applicable; $\mathrm{QD}$, once daily; SE, standard error; UMEC, umeclidinium bromide.

UMEC was generally well tolerated at all doses, with no apparent dose-related changes in vital signs. Mean absolute values on Day 7 were similar across treatments for all clinical chemistry and haematology assessments except creatine kinase, which was elevated compared with placebo for UMEC 31.25 $\mu \mathrm{g}$ QD and BID and UMEC $62.5 \mu \mathrm{g}$ QD. Most patients across all treatments had creatine kinase values within the normal range at baseline and any post-baseline assessment. The pattern of out of range values across UMEC QD treatments did not appear to be related to dose $(8 \%, 13 \%, 9 \%$, and $3 \%$ for the $15.6 \mu \mathrm{g}$, $31.25 \mu \mathrm{g}, 62.5 \mu \mathrm{g}$, and $125 \mu \mathrm{g}$ QD treatments, respectively, and $5 \%$ for placebo).

\section{Discussion}

The current study demonstrated that QD dosing with UMEC provided statistically and clinically significant improvements in lung function over 24 hours. These results extend the findings from two previous doseranging studies $[6,8]$ by demonstrating a dose ordering over a range of UMEC 15.6 to $125 \mu \mathrm{g}$ QD and further substantiating that UMEC is efficacious when administered QD. In addition, trough $\mathrm{FEV}_{1}$ results for the overlapping doses of UMEC $125 \mu \mathrm{g}$ QD and UMEC 62.5 $\mu \mathrm{g}$ QD from this study were similar to that observed in the previous dose-ranging studies (UMEC $125 \mu \mathrm{g}$ QD: 0.147 L [95\% CI:
0.077, 0.216] [6] and 0.159 L [95\% CI: 0.088, 0.229] [8] and UMEC $62.5 \mu \mathrm{g}$ QD: 0.128 L [95\% CI: 0.060, 0.196] [6]).

Consistent with published dose-response models for bronchodilators $[19,20]$, a population physiological $E_{\max }$ model characterised the relationship between UMEC dose and trough $\mathrm{FEV}_{1}$ on Day 8. A clear monotonic UMEC dose response was observed with dose ordering from the lowest $(15.6 \mu \mathrm{g})$ to highest dose $(125 \mu \mathrm{g})$. The maximum dose (125 $\mu \mathrm{g}$ UMEC QD) equated to approximately 3.4-fold $\mathrm{ED}_{50}$ of $37 \mu \mathrm{g}$ estimated in this study. The trough $\mathrm{FEV}_{1}$ response for UMEC $125 \mu \mathrm{g}$ QD $(0.183 \mathrm{~L})$ was near the maximum predicted response from the model $(0.185 \mathrm{~L})$ and was similar to the trough $\mathrm{FEV}_{1}$ response observed in the previous dose-ranging studies in patients with COPD, which ranged from 0.147 to $0.159 \mathrm{~L}[6,8]$.

A dose ordering was observed across UMEC QD dosing regimens with the UMEC $125 \mu \mathrm{g}$ QD dose demonstrating the greatest improvement in lung function measurements compared with the lower QD doses. This pattern was further supported by Bayesian analysis of trough $\mathrm{FEV}_{1}$. Although all UMEC QD doses exhibited greater improvements in serial $\mathrm{FEV}_{1}$ measures compared with placebo at Day 7, UMEC $125 \mu \mathrm{g}$ QD maintained greater increases from baseline in $\mathrm{FEV}_{1}$ across serial time points over 24 hours compared with the other QD doses. 
Table 5 0-12-hour and 12-24-hour weighted mean FEV $(\mathrm{L})$ on Day 7, (a) morning and (b) evening dose (mITT population)

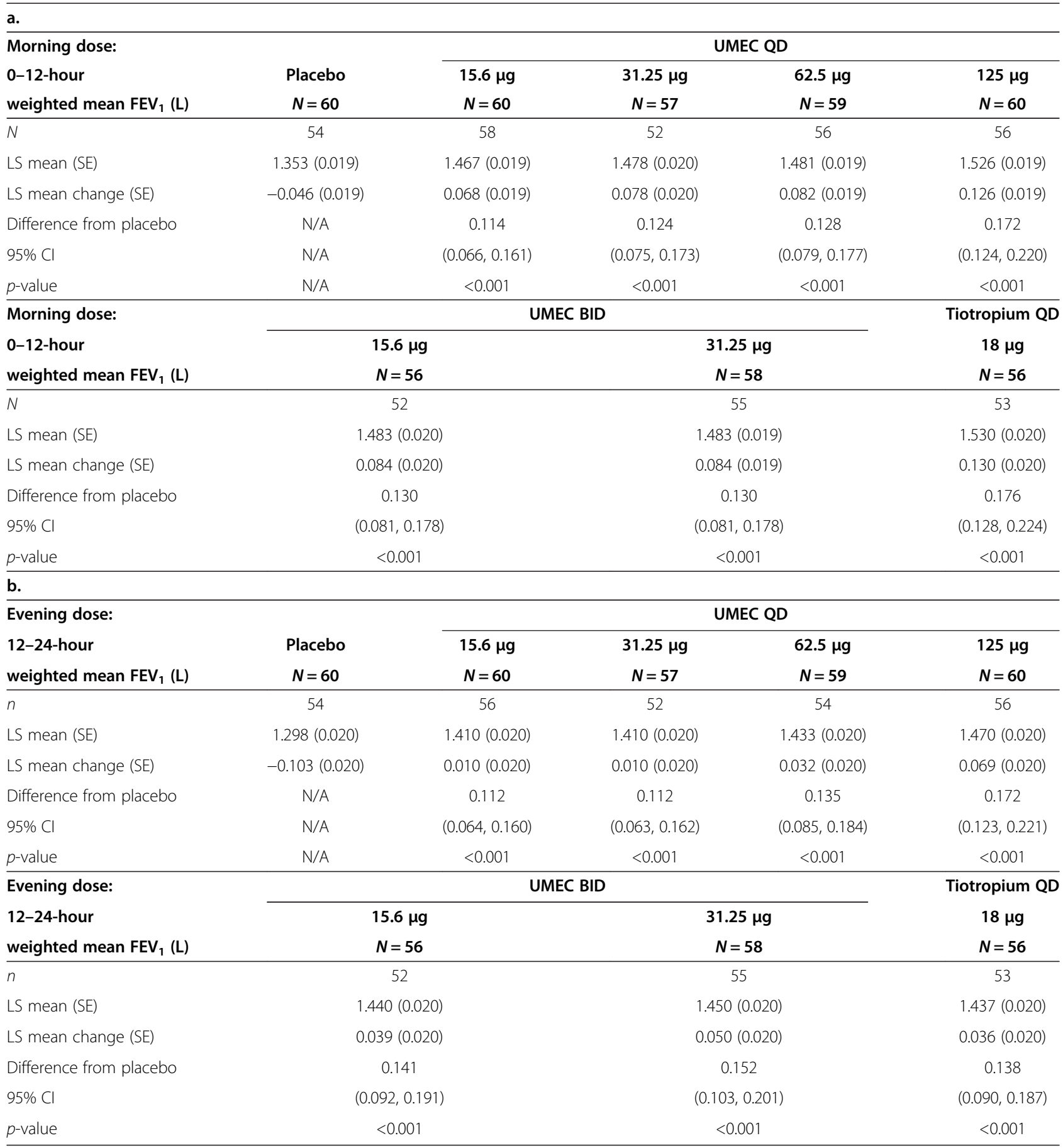

Interestingly, greater improvements in trough $\mathrm{FEV}_{1}$ were observed on Day 8 compared to improvements observed on Day 7. This may be explained by the time of drug administration. Measurements on Days 7 and 8 were taken 23 and 24 hours after dosing; however, only dosing before the Day 8 measures was observed by study staff. Furthermore, patients were required to stay overnight between Days 7 and 8. Both of these factors may explain the differences observed in trough $\mathrm{FEV}_{1}$ across the two study days. Modelling of the pooled Day 7 and 8 data provided similar results to those on Day 8 only, and the ANCOVA results on Day 7 supported those on Day 8. Although patients with COPD are known to change their responsiveness to treatment over time, individual heterogeneity in response to treatment was not examined during this study, which may be viewed as a limitation. Individual 
Table 6 Change from baseline in weighted mean $\mathrm{FEV}_{1}$ (L) difference in treatment effect compared between 12-24-hour and 0-12-hour at Day 7 (mITT population)

\begin{tabular}{|c|c|c|c|c|c|}
\hline & \multirow[b]{2}{*}{ Placebo } & \multicolumn{4}{|c|}{ UMEC QD } \\
\hline & & $15.6 \mu \mathrm{g}$ & $31.25 \mu \mathrm{g}$ & $62.5 \mu \mathrm{g}$ & $125 \mu \mathrm{g}$ \\
\hline & $N=60$ & $N=60$ & $N=57$ & $N=59$ & $N=60$ \\
\hline N & 54 & 58 & 53 & 56 & 56 \\
\hline Column vs. placebo & N/A & 0.018 & -0.007 & 0.021 & 0.010 \\
\hline \multicolumn{6}{|l|}{ Absolute difference } \\
\hline $95 \% \mathrm{Cl}$ & N/A & $(-0.040,0.076)$ & $(-0.067,0.053)$ & $(-0.038,0.080)$ & $(-0.048,0.069)$ \\
\hline \multirow[t]{4}{*}{ Ratio* } & N/A & 1.176 & 0.943 & 1.162 & 1.059 \\
\hline & \multicolumn{4}{|c|}{ UMEC BID } & Tiotropium QD \\
\hline & \multicolumn{2}{|c|}{$15.6 \mu \mathrm{g}$} & \multicolumn{2}{|c|}{$31.25 \mu \mathrm{g}$} & $18 \mu \mathrm{g}$ \\
\hline & \multicolumn{2}{|c|}{$N=56$} & \multicolumn{2}{|c|}{$N=58$} & $N=56$ \\
\hline N & \multicolumn{2}{|c|}{52} & \multicolumn{2}{|c|}{55} & 53 \\
\hline Column vs. placebo & \multicolumn{2}{|c|}{0.019} & \multicolumn{2}{|c|}{0.028} & -0.036 \\
\hline \multicolumn{6}{|l|}{ Absolute difference } \\
\hline $95 \% \mathrm{Cl}$ & \multicolumn{2}{|c|}{$(-0.041,0.078)$} & \multicolumn{2}{|c|}{$(-0.030,0.087)$} & $(-0.095,0.023)$ \\
\hline Ratio* & \multicolumn{2}{|c|}{1.147} & \multicolumn{2}{|c|}{1.215} & 0.793 \\
\hline
\end{tabular}

*Relative to 0-12-hour weighted mean $\mathrm{FEV}_{1}$.

Absolute differences $>0$ indicate a larger treatment effect between 12-24 hours; analysis performed using a mixed model with covariates trough mean baseline, trough period baseline, treatment, period, time and time by treatment interaction as fixed effects and subject as a random effect.

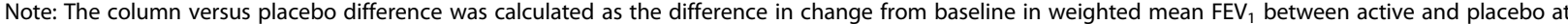
12-24 hours minus the difference in change from baseline in weighted mean FEV 1 between active and placebo at $0-12$ hours. The ratio is the difference in change from baseline in weighted mean $\mathrm{FEV}_{1}$ between active and placebo at 12-24 hours divided by the difference in change from baseline in weighted mean $\mathrm{FEV}_{1}$ between active and placebo at $0-12$ hours.

$\mathrm{BID}$, twice daily; $\mathrm{Cl}$, confidence interval; N/A, not applicable; QD, once daily; UMEC, umeclidinium bromide.

Table 7 On-treatment adverse events reported by $\geq 3 \%$ of patients within any treatment group (mITT population)

\begin{tabular}{|c|c|c|c|c|c|}
\hline \multirow{4}{*}{ Preferred term } & \multicolumn{5}{|c|}{ Number (\%) of patients } \\
\hline & \multirow{3}{*}{$\begin{array}{l}\text { Placebo } \\
N=60\end{array}$} & \multicolumn{4}{|c|}{ UMEC QD } \\
\hline & & $15.6 \mu \mathrm{g}$ & $31.25 \mu \mathrm{g}$ & $62.5 \mu \mathrm{g}$ & $125 \mu g$ \\
\hline & & $N=60$ & $N=57$ & $N=59$ & $N=60$ \\
\hline Headache & $2(3)$ & $1(2)$ & 0 & 0 & $3(5)$ \\
\hline Nasopharyngitis & 0 & $1(2)$ & 0 & 0 & $1(2)$ \\
\hline Dysgeusia & 0 & $1(2)$ & 0 & 0 & $2(3)$ \\
\hline Sinusitis & 0 & 0 & 0 & 0 & $2(3)$ \\
\hline \multirow[t]{3}{*}{ Preferred term } & \multicolumn{4}{|c|}{ UMEC BID } & Tiotropium \\
\hline & \multicolumn{2}{|c|}{$15.6 \mu \mathrm{g}$} & \multicolumn{2}{|c|}{$31.25 \mu \mathrm{g}$} & QD $18 \mu \mathrm{g}$ \\
\hline & \multicolumn{2}{|c|}{$N=56$} & \multicolumn{2}{|c|}{$N=58$} & $N=56$ \\
\hline Headache & \multicolumn{2}{|c|}{$4(7)$} & \multicolumn{2}{|c|}{$1(2)$} & 0 \\
\hline Nasopharyngitis & \multicolumn{2}{|c|}{0} & \multicolumn{2}{|c|}{0} & $2(4)$ \\
\hline Dysgeusia & \multicolumn{2}{|c|}{0} & \multicolumn{2}{|c|}{0} & 0 \\
\hline Sinusitis & \multicolumn{2}{|c|}{0} & \multicolumn{2}{|c|}{0} & 0 \\
\hline
\end{tabular}

Cut-off of $\geq 3 \%$ was based on percentage after rounding; on-treatment AEs were defined as AEs with onset within the period beginning with the first day of study drug administration through the day after the last day of study drug administration.

BID, twice daily; mITT, modified intent-to-treat; QD, once daily; UMEC umeclidinium bromide. response to treatment may have affected the interpretation of the study only because the study was small; however, the analysis was adjusted for the effect of patient, treatment and period.

The effects of UMEC QD versus BID dosing were also examined and BID regimens demonstrated small increases in the difference from placebo in some measures over QD regimens of the same total daily dose. Our study was not powered for formal comparisons between QD and BID doses. Given the small magnitude of improvement observed with BID dosing, it is considered unlikely to translate into a clinically significant benefit in efficacy. Improvements in serial $\mathrm{FEV}_{1}$ from placebo over the first 12 hours were maintained at time points over the second 12 hours for all UMEC QD doses, suggesting that QD dosing is supported for UMEC. Additionally, the ratios of evening (12-24-hour) to morning (0-12-hour) weighted mean $\mathrm{FEV}_{1}$ values were approximately 1.0 for all QD doses indicating that the 24-hour duration of effect is an intrinsic property of UMEC rather than being of a dose-related nature. The model-based analysis did not find dose regimen (QD versus BID) to be an important factor influencing dose response, which is also consistent with the previous study results [6]. This finding is not unexpected given that preclinical UMEC data demonstrated slow offrate receptor kinetics in in-vitro human M3 receptor and 
bronchial tissue, and support a QD regimen [21]. It is noteworthy that the BID regimen showed small numerical increases in $\mathrm{FEV}_{1}$ values compared with those following QD and this finding is reflected in the probability values for $15.6 \mu \mathrm{g}$ BID versus $31.25 \mu \mathrm{g}$ OD. These numerical differences in $\mathrm{FEV}_{1}$ response between regimens are generally accounted for by the model-based analysis that integrated the variability estimates between- and withinpatient across all doses [19]. Plausible reasons for the marked lower probability estimates at $31.25 \mu \mathrm{g}$ BID compared with the $62.5 \mu \mathrm{g}$ OD regimen may include study design factors, namely imbalance in patient dose allocation due to the incomplete block study design, or possible clinical under-performance of the $31.25 \mu \mathrm{g}$ BID formulation.

The LAMA tiotropium was used as an active comparator in this study as it is a well-established medication for the treatment of COPD [22]. Although the observed improvement in trough $\mathrm{FEV}_{1}$ over placebo with tiotropium was within the range of those observed with UMEC doses, tiotropium was at the lower end of the range. Nearly all UMEC QD and BID doses demonstrated improvements over placebo in trough $\mathrm{FEV}_{1}$ on Day 8 (range: $0.101-0.183 \mathrm{~L}$ ) that were numerically similar to or greater than tiotropium $(0.101 \mathrm{~L})$. However, trough $\mathrm{FEV}_{1}$ does not convey the full picture of bronchodilation offered to patients, and thus the 24-hour weighted mean and 24-hour serial $\mathrm{FEV}_{1}$ profiles were also evaluated. The 24-hour weighted mean and 24-hour serial $\mathrm{FEV}_{1}$ profiles showed UMEC doses of 62.5 and $125 \mu \mathrm{g}$ were the most similar in efficacy to tiotropium, with the bronchodilator effect of the $62.5 \mu \mathrm{g}$ dose generally less and the effect of the $125 \mu \mathrm{g}$ dose generally greater than that of tiotropium over time. These data suggest that UMEC $125 \mu \mathrm{g}$ and UMEC $62.5 \mu \mathrm{g}$ would be appropriate doses to use in future clinical studies to further assess efficacy and safety of UMEC in COPD patients.

No assessments of COPD-related symptoms were included in this study. However, rescue salbutamol on an as-needed basis for breakthrough symptoms provided a secondary marker of symptom control. Treatment with UMEC reduced rescue salbutamol use compared with placebo at all doses and a dose ordering of reduction in salbutamol use was observed for UMEC QD doses, with UMEC $125 \mu \mathrm{g}$ QD doses showing the greatest improvement. Rescue salbutamol use data are consistent with the observed improvements in lung function (i.e. the greatest reduction in use was observed with UMEC $125 \mu \mathrm{g}$ QD, which had the greatest improvement in lung function parameters). Interestingly, the greatest reduction in salbutamol occurred with tiotropium. This may be due to the design of the study in that tiotropium was administered in an open-label fashion.

This was the first study to examine the PK of lowdose UMEC (15.6 $\mu \mathrm{g}$ and 31.25 $\mu \mathrm{g}$ QD and the BID dosing regimen) in patients with COPD. In spite of the large percentage of non-quantifiable data, increased UMEC systemic exposure (in terms of AUC and $C_{\max }$ ) was seen with lower doses. Median $\mathrm{C}_{\max }$ occurred early for all UMEC doses. Systemic exposure was higher following QD dosing than BID dosing for the same total daily dose. Cross-study comparison of the steady-state data with previous studies of UMEC $62.5 \mu \mathrm{g}$ to $1000 \mu \mathrm{g}$ QD suggest that systemic exposure of UMEC was within the expected range $[6,8]$.

The safety profile was comparable between treatment groups. Overall, AEs were higher with UMEC $125 \mu \mathrm{g}$ QD dosing (18\%) than placebo or the other active treatments; however, the individual AEs observed with the UMEC $125 \mu \mathrm{g}$ QD consisted of reports of sinusitis, dysgeusia, nasopharyngitis, and headache. Headache was the most common AE across all treatments and did not appear related to active treatment. Although the AEs of nasopharyngitis, dysgeusia, and sinusitis could potentially be topical effects of LAMA treatment, these events occurred only with UMEC $15.6 \mu \mathrm{g}$ and $125 \mu \mathrm{g}$ QD dosing and so did not appear to be dose-related. Overall, UMEC was well tolerated across all dose regimens.

\section{Conclusion}

In summary, UMEC QD statistically and clinically improved lung function over 24 hours in a study population that was representative of patients with moderate-to-severe COPD. UMEC was generally well tolerated, with doseordering over UMEC QD doses of 125-15.6 $\mu$ g observed. Based on results from this study, the 62.5 and $125 \mu \mathrm{g}$ doses were considered appropriate for subsequent clinical investigation.

\section{Endnotes}

${ }^{\mathrm{a}}$ ELLIPTA $^{\mathrm{TM}}$ is a trade mark of the GlaxoSmithKline group of companies.

${ }^{\mathrm{b}} \mathrm{HandiHaler}^{\circ}$ is a registered trade mark of Boehringer Ingelheim International $\mathrm{GmbH}$.

\section{Additional files}

\section{Additional file 1: Table S1. Final dose-response model parameters for trough FEV 1 (mlTT population). \\ Additional file 2: Supplementary information. \\ Additional file 3: Figure S1. Observed vs. population/individual predictions for UMEC QD and BID regimens (mITT population). Figure S2. Predicted trough FEV $1(L)$ vs. weighted residuals (Day 8) for UMEC QD and BID regimens (mITT population).}

\section{Competing interests}

All authors are employees of and hold stock in GlaxoSmithKline.

\section{Authors' contributions}

All listed authors meet the criteria for authorship set forth by the International Committee for Medical Journal Editors. AC, MB, JB and RM were 
involved in the conception and design of the study. $A C, M B$, and $R M$ collected data. AC, MB, JB, RM and PS analysed and interpreted the data. All authors drafted and/or reviewed drafts of the manuscript and approved the final version for submission.

\section{Acknowledgements}

Editorial support (in the form of development of draft outline in consultation with the authors, development of a manuscript first draft in consultation with the authors, editorial suggestions to draft versions of this paper, assembling tables and figures, collating author comments, copyediting, fact checking, referencing, and graphic services) was provided by Tara N. Miller, $\mathrm{PhD}$, at Gardiner-Caldwell Communications and was funded by GlaxoSmithKline.

Employees of the funding body collected, analysed and interpreted the data, and the authors (all employed by the funding body) drafted and/or reviewed drafts of the manuscript, approved the final version of the manuscript, and had the final decision to submit the manuscript.

\section{Funding}

Sponsored, funded and conducted by GlaxoSmithKline (clinicaltrials.gov NCT01372410; GSK study number AC4115321). The open access article-processing charge was paid for by GlaxoSmithKline.

\section{Author details}

${ }^{1}$ Respiratory Medicines Development Center, GlaxoSmithKline, Research Triangle Park, NC 27709, USA. ${ }^{2}$ Clinical Pharmacology Modelling \& Simulation, GlaxoSmithKline, Stevenage SG1 2NY, UK. ${ }^{3}$ Respiratory Medicines

Development Centre, GlaxoSmithKline, Stockley Park, Uxbridge UB11 1BT, UK. ${ }^{4}$ Research \& Development, GlaxoSmithKline, Stockley Park, Uxbridge UB11 1BT, UK.

Received: 29 November 2012 Accepted: 31 December 2013 Published: 6 January 2014

\section{References}

1. Belmonte KE: Cholinergic pathways in the lungs and anticholinergic therapy for chronic obstructive pulmonary disease. Proc Am Thorac Soc 2005, 2:297-304

2. Roffel AF, Elzinga CR, Zaagsma J: Muscarinic $M 3$ receptors mediate contraction of human central and peripheral airway smooth muscle. Pulm Pharmacol 1990, 3:47-51.

3. Brusasco V: Reducing cholinergic constriction: the major reversible mechanism in COPD. Eur Respir Rev 2006, 15:32-36.

4. GOLD: Global Initiative for Chronic Obstructive Lung Disease. Updated 2013. http://www.goldcopd.org/uploads/users/files/GOLD_Report_2013_Feb20.pdf (Accessed January 3, 2014)

5. Cahn A, Tal-Singer R, Pouliquen IJ, Mehta R, Preece A, Hardes K, Crater G, Deans A: Safety, tolerability, pharmacokinetics and pharmacodynamics of single and repeat inhaled doses of umeclidinium in healthy subjects: two randomized studies. Clin Drug Invest 2013, 33:477-488.

6. Donohue J, Anzueto A, Brooks J, Crater G, Mehta R, Kalberg C: A Randomized, double-Blind, dose-ranging study of the novel LAMA GSK573719 in patients with COPD. Respir Med 2012, 106:970-979.

7. Tal-Singer R, Cahn T, Mehta R, Preece A, Crater G, Kelleher D, Pouliquen IJ: Initial assessment of single and repeat doses of inhaled umeclidinium in patients with chronic obstructive pulmonary disease: Two randomised studies. Eur J Pharmacol 2013, 701:40-48.

8. Decramer M, Maltais F, Feldman G, Brooks J, Harris S, Mehta R, Crater G: Bronchodilation of umeclidinium, a new long-acting muscarinic antagonist, in COPD patients. Respir Physiol Neurobiol 2013, 185:393-399.

9. Sheiner LB, Hashimoto Y, Beal SL: A simulation study comparing designs for dose ranging. Stat Med 1991, 10:303-331.

10. Church A, Beerahee M, Brooks J, Mehta R, Shah P: Umeclidinium (GSK573719) dose response and dosing interval in COPD [abstract]. Eur Respir J 2012, 40(Suppl 56):377s.

11. Celli BR, MacNee W: Standards for the diagnosis and treatment of patients with COPD: a summary of the ATS/ERS position paper. Eur Respir J 2004, 23:932-946.

12. Hankinson JL, Odencrantz JR, Fedan KB: Spirometric reference values from a sample of the general US population. Am J Resp Crit Care Med 1999, 159:179-187.
13. Hankinson JL, Kawut SM, Shahar E, Smith LJ, Hinckley MD, Stukovsky K, Barr RG: Performance of American Thoracic Society-recommended spirometry reference values in a multiethnic sample of adults: the multi-ethnic study of atherosclerosis (MESA) lung study. Chest 2010, 137:138-145.

14. WMA Declaration of Helsinki - Ethical Principles for Medical Research Involving Human Subjects. Adopted by the 18th WMA General Assembly, Helsinki, Finland, June 1964 and amended (latest) by the 59th WMA General Assembly, Seoul, Korea, October 2008. http://www.wma.net/en/30publications/ 10policies/b3/index.html (Accessed January 3, 2014).

15. Miller MR, Hankinson J, Brusasco V, Burgos R, Casaburi R: Standardisation for spirometry. Eur Respir J 2005, 26:319-338.

16. Vong C, Bergstrand M, Karlson MO: Rapid sample size calculations for a defined likelihood ratio test-based power in mixed effects models [abstract]. Annu Meet Popul Approach Group Eur 2010, 1863:19.

17. European Medical Agency guidelines: Guideline on reporting the results of population pharmacokinetic analyses. CHMP/EWP/185990/06. 2007. http:// www.ema.europa.eu/docs/en_GB/document_library/Scientific_guideline/ 2009/09/WC500003067.pdf (Accessed January 3, 2014).

18. Food and Drug Administration (FDA): Guidance for industry: population pharmacokinetics. U.S. Center for Drug Evaluation and Research; 1999. http://www.fda.gov/downloads/ScienceResearch/SpecialTopics/ WomensHealthResearch/UCM133184.pdf (Accessed January 3, 2014).

19. Renard D, Looby M, Kramer B, Lawrence D, Morris D, Stanski DR: Characterization of the bronchodilatory dose response to indacaterol in patients with chronic obstructive pulmonary disease using model-based approaches. Respir Res 2011, 12:54.

20. Wang Y, Lee JY, Michele T, Chowdhury BA, Gobburu JV: Limitations of model based dose selection for indacaterol in patients with chronic obstructive pulmonary disease. Int I Clin Pharmacol Ther 2012, 50:622-630.

21. Lainé DI, Luttmann MA, Foley JJ, Dehaas CJ, Kotzer CJ, Salmon M, Rumsey WL: The pre-clinical pharmacology of the inhaled muscarinic antagonist GSK573719 predicts once-daily clinical dosing [abstract]. Eur Respir J 2011 38(Suppl 55):613s.

22. Pfizer Inc: Spiriva HandiHaler prescribing information. New York, NY, USA; 2006. http://bidocs.boehringer-ingelheim.com/BIWebAccess/NiewServlet.ser? docBase=renetnt\&folderPath=/Prescribing+Information/PIs/Spiriva/Spiriva. pdf (Accessed January 3, 2014).

doi:10.1186/1471-2466-14-2

Cite this article as: Church et al: Dose response of umeclidinium administered once or twice daily in patients with COPD: a randomised cross-over study. BMC Pulmonary Medicine 2014 14:2.

\section{Submit your next manuscript to BioMed Central and take full advantage of:}

- Convenient online submission

- Thorough peer review

- No space constraints or color figure charges

- Immediate publication on acceptance

- Inclusion in PubMed, CAS, Scopus and Google Scholar

- Research which is freely available for redistribution 